\title{
COMPREHENSIVE EVALUATION OF THE ANTIOXIDANT ACTIVITY OF SIX WILD EDIBLE MUSHROOM SPECIES
}

Marija V. Dimitrijević*, Violeta D. Mitić, Vesna P. Stankov-Jovanović, Jelena S. Nikolić, Gordana S. Stojanović

University of Niš, Faculty of Sciences and Mathematics, Department of Chemistry, Niš, Serbia

(ORIGINAL SCIENTIFIC PAPER) UDC 582.28: $66.094 .3 .097 .8+547.56$
The present study describes antioxidant properties of six wild mushrooms (Boletus edulis Bull., Boletus regius Krombh., Leccinum pseudoscaber Kallenb., Boletus impolitus Fr., Lactarius volemus Fr., and Lactarius deliciosus (L.) Gray) collected in Serbia. The antioxidant properties were assessed through the evaluation of the reducing power and radical scavenging ability of the samples. The Boletus regius sample revealed the best results in almost all antioxidant activity assays, with the highest reducing power and the highest scavenging activity, $33.0 \pm 0.1 \mathrm{mg} T E / \mathrm{g} \mathrm{dw}$ in DPPH; $1.35 \pm 0.02 \mathrm{mg} \mathrm{AAE} / \mathrm{g}$ dw in TRP; $13.42 \pm 0.08 \mathrm{mg}$ Fe/g dw in FRAP; $37.5 \pm 0.2$ $\mathrm{mg}$ TE/g dw in CUPRAC; 243.6 $\pm 5.1 \mathrm{mg} \mathrm{GAE} / \mathrm{g}$ dw in TPC. On the contrary, Lactarius volemus showed the lowest antioxidant activity. The results indicate that the analyzed wild mushroom species possess reductive capabilities, and they could be a potential source of antioxidants. The study was raised to the next level using a chemometric analysis, a principal component analysis to display the correlation between the antioxidant activity and different mushroom species.
Keywords: mushrooms, antioxidant activity, phenol content, chemometric analysis.

\section{Introduction}

Despite great progress in modern medicine in recent times, a natural source of antioxidants still plays an important role in a medical treatment. A huge number of medicinal plants have been investigated for their antioxidant and other activities. Antioxidants, both synthetic and natural, can be effective for helping the human body in reducing oxidative damage by reactive oxygen species (ROS) [1]. Today, in order to find a dietary source full of antioxidants that can help human body to reduce oxidative damage, different plant and mushroom species have been explored. The investigation of mushrooms and their extracts antioxidant activity and the content of antioxidant compounds is extremely current scientific subject.

The investigation of mushrooms and their extracts antioxidant activity and the content of antioxidant compounds is very actual scientific subject [2]. The antioxidant activity of some mushrooms extracts were also studied by other researchers. For example, Kosanić et al. [3] found a strong antioxidant activity for methanol extracts from $B$. edulis and L. pseudoscaber. L. deliciosus is one of the most popular mushrooms because they are an excellent source of antioxidant compounds like polyphenols [4].

Mushrooms have a long tradition of use in many countries. People usually use edible mushrooms for meals, consuming them fresh, prepared or even as spices. Edible mushrooms are food full of protein, crude fiber, minerals and vitamins, with low fat and cholesterol contents, so they could be an ideal source of nutritional ingredients. Mushrooms have a low glycemic index which is especially beneficial for diabetics, a very low sodium ( $\mathrm{Na}$ ) concentration which is beneficial for hypertensive patients and a high content of potassium (K) and phosphorus $(P)$ which is an important orthomolecular aspect [5]. Also, they are sources of beneficial bioactive substances that contribute to good health [3]. Edible mushrooms have got the attention as a commercial source of antioxidants. They can be used directly in enhancement of antioxidant defenses through dietary supplementation to reduce the level of oxidative stress. Mushrooms produce and store a wide range of secondary metabolites which includes phenolic compounds. Phenolic compounds can be classified as simple phenols and phenolic acids such as gallic acid, benzoic acid, syringic acid, chlorogenic acid and other associates, and polyphenols which are classified into many groups such as flavonoids, tannins, stilbenes, and so on [6].

The objective of this work was to evaluate the antioxidant properties of six mushroom species (Boletus edulis Bull., Boletus regius Krombh., Boletus impolitus Fr., Leccinum pseudoscaber Kallenb, Lactarius volemus Fr., and Lactarius deliciosus (L.) Gray). In Serbia, these mushroom species are in use as delicious food. For these mushrooms, the antioxidant activity was compre-

\footnotetext{
*Author address: Marija Dimitrijević, Faculty of Sciences and Mathematics, Department of Chemistry, University of Niš, Višegradska 33, 18000 Niš, Serbia

E-mail: marija.dimitrijevic@pmf.edu.rs

The manuscript received: November, 08, 2016.

Paper accepted: December, 05, 2016.
} 
hensively evaluated measuring free radical scavenging capacity (ABTS and DPPH), ferric reducing antioxidant capacity (FRAP), total reducing power (TRP), cupric reducing antioxidant capacity (CUPRAC) and total phenolic content (TP).

One more reason to conduct this research is that antioxidant activities of some mushrooms have not been reported previously.

\section{Methods and materials}

\section{Sample collection and preparation}

Fruiting bodies were collected in the unpolluted region Ploče, near the town of Niš, the Republic of Serbia. To overcome variability of environmental conditions, mushroom samples were collected at four experimental points and from every experimental point three mushrooms of each examined species were taken. Mushrooms were cleaned, taxonomically identified and then cut and dried at room temperature. They were stored in paper bags and packed loosely with provision of aeration until the analysis started.

\section{Chemicals and instruments}

2, 2-diphenyl-1-picrylhydrazyl (DPPH), 2, 2'-azinobis (3-ethylbenzothiazoline-6-sulphonic acid) (ABTS), $\mathrm{FeCl}_{3} \cdot 6 \mathrm{H}_{2} \mathrm{O}$, Folin-Ciocalteu reagent, 6-hydroxy-2,5,7,8tetramethylchroman-2-carboxylic acid (Trolox) and methanol were purchased from Sigma Co. St. Louis, Missouri, USA.

The following chemicals (p.a. grade): neocuproine (2, 9-dimethyl-1, 10-phenanthroline), $\mathrm{CuCl}_{2} \times 2 \mathrm{H}_{2} \mathrm{O}, \mathrm{Na}_{2} \mathrm{CO}_{3}$, $\mathrm{HCl}, 2$, 4, 6-tris (2-pyridyl)-s-triazine (TPTZ), $\mathrm{K}_{3}\left[\mathrm{Fe}(\mathrm{CN})_{6}\right]$, phosphate buffer $\left(\mathrm{NaH}_{2} \mathrm{PO}_{4}-\mathrm{Na}_{2} \mathrm{HPO}_{4}\right)$, ammonium acetate buffer, $\mathrm{CCl}_{3} \mathrm{COOH}, \mathrm{K}_{2} \mathrm{~S}_{2} \mathrm{O}_{8}, \mathrm{FeSO}_{4} \cdot 7 \mathrm{H}_{2} \mathrm{O}$, dimethyl sulphoxide (DMSO), were purchased from Merck, Darmstadt, Germany.

Spectrophotometric assays were performed on a double-beam UV-VIS spectrophotometer Perkin EImer lambda 15 (Massachusetts, USA). Each of the mushroom samples was analyzed in triplicate.

Extraction and yield determination of the extracts

The preparation of methanol extracts of mushrooms was done as follows: a three $\mathrm{g}$ fine dried mushroom sample was ground in a mill and extracted with $30 \mathrm{~mL}$ of methanol. The extraction was performed four times in an ultrasonic bath for 15 minutes at $25{ }^{\circ} \mathrm{C}$. The solvent extraction is the most frequently used technique for isolation of plant antioxidant compounds [7]. The extracts were filtered and then evaporated to dryness $\left(35^{\circ} \mathrm{C}\right)$ under reduced pressure in a rotary evaporator. For the entire analysis, compounds of the extract were dissolved in dimethyl sulfoxide (DMSO). The extracts were kept in the dark at $4{ }^{\circ} \mathrm{C}$ until the time of analysis.

The yields of concentrated dried extracts of mushrooms were calculated based on the dry weight as:

$$
\operatorname{Yield}(\%)=\frac{\left(W_{1} \cdot 100\right)}{W_{2}}
$$

Where:

$W_{1}$ is the weight of the evaporated extract

$\mathrm{W}_{2}$ is the weight of the ground mushroom used for the extraction process

Determination of total phenolic content

The total phenolic content was determined using FolinCiocalteu reagent as originally described by Singleton and Orthofer [8]. The absorbance was measured at $750 \mathrm{~nm}$ using a spectrophotometer. Gallic acid solutions in methanol were used as standards and the measurement was compared to the calibration curve of gallic acid (GA). The results were expressed as $\mathrm{mg}$ gallic acid equivalents (GAE) per $g$ of the dry weight (mg GAE/g dw).

\section{Measurement of in vitro antioxidant activity}

DPPH radical scavenging activity was determined according to the method of Mitic et al [9]. Stable DPPH radicals are widely used to evaluate the antioxidant activities of proton-donating substances according to the hydrogen donating ability [10]. Absorbance was measured at $515 \mathrm{~nm}$ and all determinations were performed in triplicate. The DPPH radical is long-lived organic nitrogen radical with a deep purple colour [11]. As opposed to other tests, higher absorbance of the reaction mixture indicates a lower antioxidant activity. The reason for this occurrence is the lack of antioxidants in the analyzed sample that reduced purple colour DPPH reagent and thus decreased the absorbance which would mean more activity. Radical scavenging activity was determined from the calibration curve, which was drawn by using Trolox as the positive control, in the concentration 1-16 $\mathrm{mmol} / \mathrm{L}$ and expressed in $\mathrm{mg}$ of Trolox equivalents (TE) per $\mathrm{g}$ dry extract weight (mg TE/g dw).

\section{ABTS radical "scavenging" activity}

ABTS radical scavenging activity was performed according to the method of Re et al. [12]. This method is similar to DPPH assay. Antioxidant molecules react with stable ABTS radical, inhibit harmful reactions and suppress the colour development. After incubation at room temperature, the reduction in absorbance was measured at $734 \mathrm{~nm}$. The results are expressed as mg of Trolox equivalents (TE) per $\mathrm{g}$ dry extract weight (mg TE /g dw).

Ferric-reducing antioxidant power (FRAP) assay

Ferric reducing antioxidant power assay was performed using the method of Benzie and Strain [13] and it is based on the reduction of ferric iron in the tripyridyltriazine complex to the blue ferrous form at low $\mathrm{pH}$. This reduction is monitored by measuring the colour change during absorption at $595 \mathrm{~nm}$. The final results are expressed as $\mathrm{mg}$ of $\mathrm{Fe}$ (II) equivalents per $\mathrm{g}$ dry weight (mg Fe/g dw) obtained by comparing the absorption change in the test mixture with the doses obtained from the Fe (II) standard calibration curve in the con- 
centration 2.5-25 mmol/l.

Total reducing power (TRP) assay

The reducing power of the extracts was determined by the method of Oyaizu [14]. This method is based on the ability of antioxidants to reduce Fe (III) hexacyanate to Fe (II) hexacyanate which leads to the increase in the absorbance of the reaction mixtures. The absorbance was measured at $700 \mathrm{~nm}$ against the blank sample and the results were expressed as $\mathrm{mg}$ ascorbic acid equivalents per $\mathrm{g}$ of dry extract weight (mg AAE/g dw).

Cupric reducing antioxidant capacity (CUPRAC) assay

The CUPRAC assay was performed using the method of Apak et al. [15]. The method is based on the reduction of a cupric neocuproine complex $(\mathrm{Cu}(\mathrm{II})-\mathrm{Nc})$ by antioxidants to the cuprous form $(\mathrm{Cu}(\mathrm{I})-\mathrm{Nc})$. The CUPRAC reagent is much more stable and easily accessible than chromogenic radical reagents (e.g. ABTS and DPPH) [16]. After 30 min incubation at room temperature, the absorbance was measured at $450 \mathrm{~nm}$. Trolox was used as a standard and the results were expressed as $\mathrm{mg}$ Trolox equivalents per $\mathrm{g}$ of dry weight $(\mathrm{mg}$ $\mathrm{TE} / \mathrm{g} \mathrm{dw}$ ).

\section{Antioxidant Composite Index - ACl}

The results of the antioxidant activity measured by different methods is difficult to compare with each other, primarily because of different mechanisms of action, different units used to express the results and very different techniques for the preparation of the investigated samples. To reduce the results of antioxidant activities obtained with different methods at comparable values, we calculated the total antioxidant index ( $\mathrm{ACl}$ - Antioxidant Composite Index). An overall antioxidant potency composite index was determined by assigning all assays an equal weight, assigning an index value of 100 to the best score for each test, and then calculating an index score for all other samples within the test as follows: antioxidant index score=[(sample score/best score) $\times 100]$; the average of all six tests for each samples was then taken for the antioxidant potency composite index [17].

\section{Statistical analysis}

Statistical analyses were performed with Statistica 8 (StatSoft, Tulsa) software packages. All chemical analyses were carried out in triplicate and the results expressed as mean \pm standard deviation (SD). The significance of differences was defined at $p<0.05$. Principal component analysis (PCA) was carried out by the same software in order to connect antioxidant activity assays and the analysed mushrooms.

\section{Results and discussion}

Crude extract \% yield

Extract yields and resulting antioxidant activities of the mushroom materials strongly depend on the nature of the solvent (used for extraction) due to the presence of different antioxidant compounds with varied chemical characteristics and polarities that may or may not be soluble in a particular solvent [5]. All mushroom species were carried out at the same procedures and the results are given as a percentage of the original weight of the crude sample (Table 1). The best yield was obtained for B. impolitus extract $(19.08 \%)$ while $L$. deliciosus extract had the least one $(8.78 \%)$. Polar solvents were used for the extraction of phenolic compounds. The most suitable solvents are aqueous mixtures containing ethanol, methanol, acetone, and ethyl acetate (hot or cold) [18] If we compare these results with the previous research, Dimitrijevic et al. [19] where ethanol is used as a solvent, it could be concluded that methanol is a better solvent and the extracts obtained in this way exhibit a better antioxidant activity.

Table 1. \% Crude extract yield of the mushrooms and antioxidant potency composite index $(\mathrm{ACl})$ for six different methods

\begin{tabular}{ccccccccc}
\hline $\begin{array}{c}\text { Mushroom } \\
\text { species }\end{array}$ & Yield (\%) & DPPH & ABTS & TRP & CUPRAC & FRAP & TPC & Average \\
\hline B. edulis & 11.86 & 67.60 & 37.29 & 69.04 & 86.81 & 60.87 & 70.72 & 65.39 \\
B. regius & 10.59 & 100 & 53.74 & 100 & 100 & 100 & 100 & 92.29 \\
L. pseudoscaber & 14.49 & 33.15 & 14.29 & 34.73 & 34.22 & 37.22 & 39.06 & 32.11 \\
B. impolitus & 19.08 & 36.33 & 17.16 & 28.29 & 34.40 & 52.75 & 28.03 & 32.83 \\
L. volemus & 9.14 & 5.56 & 77.09 & 13.01 & 12.12 & 0 & 17.19 & 20.83 \\
L. deliciosus & 8.78 & 7.98 & 100 & 29.31 & 35.86 & 0 & 24.09 & 32.87 \\
\hline
\end{tabular}

Table 2. Antioxidant capacities of selected mushrooms determined by six different methods (mean \pm standard deviation, $\mathrm{n}=3$ )

\begin{tabular}{ccccccc}
\hline & B. edulis & B. regius & L. pseudoscaber & B. impolitus & L. volemus & L. deliciosus \\
\hline DPPH & 22.3 & 33.0 & 10.9 & 11.9 & 1.84 & 2.63 \\
(mg TE/g dw) & \pm 0.1 & \pm 0.1 & \pm 0.1 & \pm 0.1 & \pm 0.08 & \pm 0.08 \\
ABTS & 3.06 & 4.41 & 1.17 & 1.41 & 6.33 & 8.21 \\
(mg TE/g dw) & \pm 0.06 & \pm 0.07 & \pm 0.08 & \pm 0.06 & \pm 0.08 & \pm 0.09 \\
TRP & 0.93 & 1.35 & 0.467 & 0.381 & 0.175 & 0.394 \\
(mg AAE/g dw) & \pm 0.01 & \pm 0.02 & \pm 0.006 & \pm 0.007 & \pm 0.008 & \pm 0.004 \\
CUPRAC & 32.5 & 37.5 & 12.8 & 12.9 & 4.54 & 13.4 \\
(mg TE/g dw) & \pm 0.2 & \pm 0.2 & \pm 0.1 & \pm 0.1 & \pm 0.05 & \pm 0.1 \\
FRAP & 8.17 & 13.42 & 4.99 & 7.08 & 0 & 0 \\
(mg Fe/g dw) & \pm 0.05 & \pm 0.08 & \pm 0.06 & \pm 0.08 & \pm 0 & \pm 0 \\
TPC & 172.26 & 243.6 & 95.14 & 68.3 & 41.9 & 58.7 \\
(mg GAE/g dw) & \pm 4.01 & \pm 5.1 & \pm 2.01 & \pm 3.9 & \pm 1.1 & \pm 1.1 \\
\hline
\end{tabular}


Total phenolic content (TPC)

It has been reported that the antioxidant activity was well correlated with the content of phenolic compounds [20]. Phenolic compounds are secondary metabolites that can act as antioxidants due to their ability to donate hydrogen, quench singlet oxygen and act as metal chelators [21]. Therefore, it was important to quantify their contents in mushrooms and the results (expressed as milligram equivalent of gallic acid per gram of dry extract) are presented in Table 2. The highest amount of the phenolic content was found in $B$. regius extract (243.6 mg GAE/g dw) followed by > B. edulis (172.26 mg GAE/g dw), L. pseudoscaber (95.14 mg GAE/g dw), B. impolitus (68.3 mg GAE/g dw), L. deliciosus $(58.7 \mathrm{mg}$ $\mathrm{GAE} / \mathrm{g} \mathrm{dw}$ ) and $L$. volemus (41.9 mg GAE/g dw) extracts.

The obtained results confirmed the connection between TPC and the antioxidant activity. Therefore, B. regius extract showed the best antioxidant activity in four of the five applied methods. The results for $B$. regius extract achieved in this study were in an agreement with the results of Leal et al. [22].

\section{Antioxidant activities}

There is a large number of antioxidant assays which can be used to evaluate the antioxidant activity. The methods based on the reducing power and the ability of "scavenging" are most commonly used for the evaluation of antioxidant activities of extracts. The principal tests include: the Folin-Ciocalteau assay, which is specific to determine phenolic compounds content; the ABTS and DPPH assays, which evaluate the antioxidant power toward inhibition of free radicals, and the ferric reducing antioxidant power (FRAP) assay, based on a redox reaction occurring between the substrate (electron donor) and $\mathrm{Fe}^{3+}$ ions (electron acceptor), producing $\mathrm{Fe}^{2+}$ ions [23]. To obtain comparable values, the results of ABTS, DPPH and CUPRAC assays were expressed as Trolox equivalents.

\section{Free radical scavenging activity}

Free radical scavenging assay has mechanisms based on inhibition of lipid oxidation commonly used to estimate the antioxidant activity. In this study, the radical scavenging of mushroom extracts was tested using a methanol solution of the 'stable' free radical, DPPH [24] and ABTS. The results are shown in Table 2. It can be seen that scavenging activity of six different methanol extracts is significantly different. Boletus regius extract showed the strongest DPPH radical scavenging effect (33.0 $\mathrm{mg} \mathrm{TE} / \mathrm{g} \mathrm{dw}$ ) while the lowest activity of DPPH radical-scavenging was obtained from $L$. volemus extract $(1.84 \mathrm{mg} \mathrm{TE} / \mathrm{g} \mathrm{dw})$. The results obtained by ABTS method showed deviation from the results obtained by DPPH method. Among the tested mushroom samples, the extracts of $L$. deliciosus showed the highest scavenging activity $(8.21 \mathrm{mg} \mathrm{TE} / \mathrm{g} \mathrm{dw})$, followed by the extracts obtained from $L$. volemus $(6.33 \mathrm{mg} \mathrm{TE} / \mathrm{g} \mathrm{dw}$ ). Pre- sent ABTS value for $L$. deliciosus was also comparable with the previous report [4].

Total reducing power (TRP) assay

The reducing capacity may be a significant index of the antioxidant activity [10]. The yellow colour of the test solution changes to various shades of green and blue depending on the reducing power of each compound [25]. The results of this assay are presented in Table 2.

By comparing the reducing capacity of six different mushrooms, the methanol extract of $B$. regius showed the highest total reducing power (1.35 $\mathrm{mg} \mathrm{AAE} / \mathrm{g} \mathrm{dw}$ ), while $L$. volemus showed a much lower value $(0.175 \mathrm{mg}$ $A A E / g d w)$.

\section{CUPRAC}

In the present study, the antioxidant activity was measured by the CUPRAC method. In this method, the capacity of an antioxidant was evaluated by measuring the produced colour at nearly physiological $\mathrm{pH}(\mathrm{pH}$ of ammonium-acetate buffer) which is opposite to the acidic conditions ( $\mathrm{pH} 3.6)$ needed for the FRAP method, or basic conditions ( $\mathrm{pH} 10)$ necessary for Folin assay[16]. Among methanol extracts of six mushrooms, $B$. regius and $B$. edulis showed the highest value 37.5 and 32.5 $\mathrm{mg} \mathrm{TE} / \mathrm{g} \mathrm{dw}$, respectively (Table 2 ), just as expected taking into consideration the total phenolic content.

\section{FRAP}

The antioxidant activity (FRAP) was evaluated for methanol extracts of $B$. regius, $B$. edulis, $B$. impolitus and $L$. pseudoscaber while it could not be measured for the extracts of $L$. volemus and $L$. deliciosus (Table 2 ). During mixing the extract with FRAP, the reagent residue appeared. The highest values for $\mathrm{B}$. regius extract (13.42 $\mathrm{mg} \mathrm{Fe} / \mathrm{g} \mathrm{dw}$ ) can be explained by their high level of phenolic compounds in comparison with other analysed mushrooms. Jaworska et al. [26] determined the antioxidant activity of edible mushrooms, including $B$. edulis. Our result for $B$. edulis is in accordance with the value obtained in the mentioned paper.

\section{Antioxidant potency composite index-ACl}

Bearing in mind that the antioxidant activity of the analysed mushrooms is expressed in different units, it is hard to compare the same methods; the $\mathrm{ACl}$ value equates all units and gives the values that are comparable. The $\mathrm{ACl}$ values are shown in Table 1. As it could be seen, $B$. regius showed the best antioxidant capacity, 92.29 according to all six applied methods. L. volemus showed the lowest $\mathrm{ACl}$ value (20.83).

The correlation coefficients (R2) between the estimations of the antioxidant capacity made by different methods (Table 1 ) and the concentrations of total phenols should be presented.

\section{Statistic analysis}

PCA involves a mathematical procedure that identi- 
fies patterns in data, and expresses them in such a way as to highlight similarities and differences [27]. So, in this manuscript, PCA was applied to the data set of six different mushroom species ( $B$. edulis, $B$. regius, $B$. impolitus, $L$. pseudoscaber, $L$. volemus and $L$. deliciosus) to separate the samples according to similarity of the antioxidant activity. This technique is very useful because it reduces original variables (DPPH, ABTS, CUPRAC, TRP, FRAP and TPC) based on Principal Component and gives the relationship between analyzed mushroom species and applied methods. The results obtained for each method were adopted as columns and the mushroom species as rows. For interpretation of PCA results, the Kaiser criterion [28] has been useful to determine the number of Principal Components.

Two principal components were extracted because they have eigenvalues higher than 1.0, as suggested by the Kaiser criterion. Eigenvalues give the measure of the variance accounted by the corresponding eigenvectors (components) [29]. Principal component 1 (PC1) explained up to $81.32 \%$ of total variance and PC2 explained $17.09 \%$ (Figure 1a and $1 b$ ).

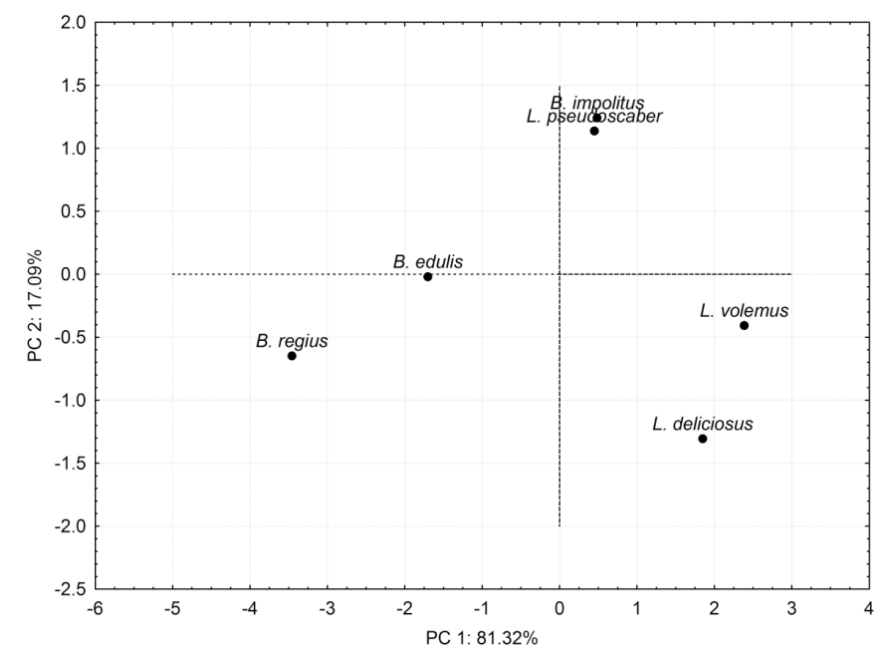

Figure 1a. Score plot obtained from PCA of the antioxidant activity and the phenolic content of methanol extracts of six wild mushroom species.

DPPH, FRAP, CUPRAC, TRP and TPC are strongly positive correlated and grouped on the left side of the plot (Figure 1a). ABTS is found in opposition to DPPH, FRAP, CUPRAC, TRP and TPC. $B$. regius is on the negative side of the plot from all others because it has the highest negative loadings on PC1 (-3.46). It is expected because this mushroom was proved to have the highest antioxidant activity and therefore stands out from other mushrooms. In contrast, $L$. deliciosus has the highest negative loadings on PC2 (-1.31). B. regius and B. edulis are located on the third quadrants (Figure 1a) and this suggests that these mushrooms have the highest antioxidant activity (Table 2 ). In contrast, $B$. regius and $B$. edulis have low values for ABTS, which is collocated diametrically opposite to DPPH, FRAP, CUPRAC, TRP and
TPC. The location of ABTS in the loading plot confirmed no significant correlation with other assays. L. deliciosus and $L$. volemus are located diametrically opposite to $B$. regius and $B$. edulis indicating a low antioxidant activity but a high value of ABTS assay. The use of score (Figure $1 \mathrm{a})$ and loading plots (Figure 1b) from the principal component analysis allowed characterization of the location sampling of mushrooms based on their antioxidant activity and total phenolic concentration.

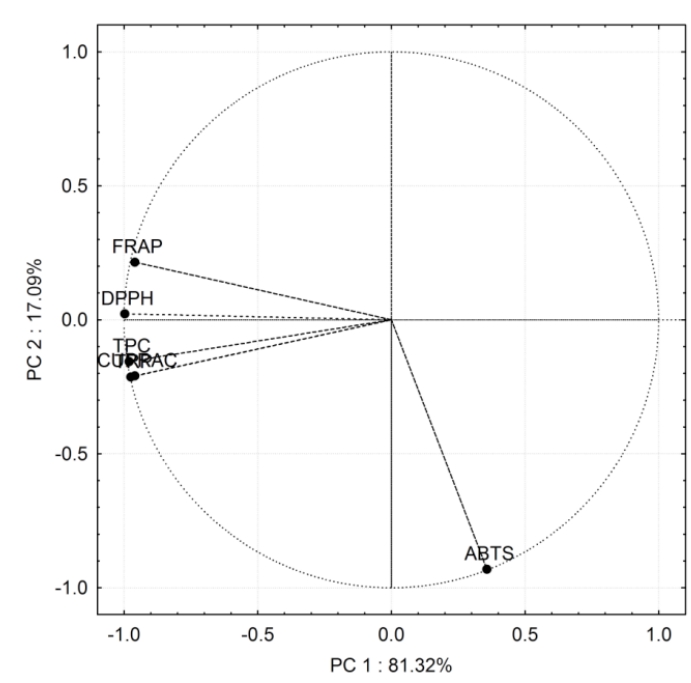

Figure 1b. Loading plot obtained from PCA of five antioxidant tests of methanol extracts of six wild mushroom species.

\section{Conclusion}

As far as our literature survey could be certain, there is no report on the antioxidant activity of $B$. impolitus in the literature. Therefore, the data given for the mushroom here could be assumed as the first report on this topic.

In conclusion, the results reveal that the investigated wild mushroom extracts possess the antioxidant activity against various antioxidant systems. The highest total phenols content, the highest scavenging activity and the highest reductive capabilities have been determined for the $B$. regius mushroom extract. Studies thus provide the precise antioxidant status of six mushroom species (Boletus edulis Bull., Boletus regius Krombh., Leccinum pseudoscaber Kallenb., Boletus impolitus Fr., Lactarius volemus Fr., and Lactarius deliciosus (L.) Gray) and can serve as a useful database for the selection of mushrooms as a natural antioxidant.

\section{Acknowledgments}

The research was supported by the Ministry of Education, Science and Technological Development of the Republic of Serbia (OI 172047). Marija Dimitrijević is grateful to the Ministry of Education, Science and Technological Development of the Republic of Serbia for providing scholarships for researchers. 


\section{Reference}

[1] M. Kosanić, B. Ranković, J. Vu kojević, Antioxidant properties of some lichen species, Journal of Food Science and Technology, 48 (5) (2011) 584-590.

[2] S. Vidović, I. Mujić, Z. Zeković, Ž. Lepojević, V. Tumbas, A. Mujić, Antioxidant Properties of Selected Boletus Mushrooms, Food Biophysics, 5 (1) (2010) 49-58.

[3] M. Kosanić, B. Ranković, M. Dašić, Mushrooms as Possible Antioxidant and Antimicrobial Agents, Iranian Journal of Pharmaceutical Research, 11(4) (2012) 10951102.

[4] K. Pogoń, G. Jaworska, A. Duda-Chodak, I. Maciejaszek, Influence of the Culinary Treatment on the Quality of Lactarius deliciosus, Foods, 2(2) (2013) 238-253.

[5] S.T. Chang, S.P. Wasser, The role of culinary-medicinal mushrooms on human welfare with a pyramid model for human health. International Journal of Medicinal Mushrooms, 14 (2) (2012) 95-134.

[6] M.Y. Kim, P. Seguin, J.K. Ahn, J.J. Kim, S.C. Chun, E.H. Kim, S.H. Seo, E.Y. Kang, S.L. Kim, Y.J. Park, H.M. Ro, I.M. Chung, Phenolic compound concentration and antioxidant activities of edible and medicinal mushrooms from korea, Journal of Agricultural and Food Chemistry, 56 (6) (2008) 7265-7270.

[7] B. Sultana, F. Anwar, M. Ashraf, Effect of extraction solvent/technique on the antioxidant activity of selected medicinal plant extracts, Molecules, 14 (6) (2009) 21672180.

[8] V.L. Singleton, R. Orthofer, R.M. Lamuela-Raventós, Analysis of total phenols and other oxidation substrates and antioxidants by means of Folin-Ciocalteu reagent, Methods in Enzymology, 299 (1999) 152-178.

[9] V. Mitic, V. Stankov Jovanovic, M. Dimitrijevic, J. Cvetkovic, S. Simonovic and S. Nikolic Mandic, Chemometric analysis of antioxidant activity and anthocyanin content of selected wild and cultivated small fruit from Serbia, Fruits, 69 (5) (2014) 413-422.

[10] J. Y. Yeh, L. H. Hsieh, K. T. Wu, C. F. Tsai, Antioxidant properties and antioxidant compounds of various extracts from the edible basidiomyceteGrifolafrondosa (Maitake), Molecules, 16(4) (2011) 3197-211.

[11] K. Pyrzynska, A. Pekal, Application of free radical diphenylpicrylhydrazyl (DPPH) to estimate the antioxidant capacity of food samples, Analytical Methods, 5(17) (2013) 4288-4295

[12] R. Re, N. Pellegrini, A. Proreggente, A. Pannala, M. Yang, Antioxidant activity applying an improved ABTS radical cation decolorization assay, Free Radical Biology and Medicine, 26(9-10) (1999) 1231-1237.

[13] I. F. F. Benzie, J. J. Strain, The ferric reducing ability of plasma (FRAP) as a measure of 'Antioxidant Power': The FRAP assay, Analytical Biochemistry, 239(1) (1996) 70-76.

[14] M. Oyaizu, Study on the browning substance for antioxidation of the glucosamine browning substance, 1986. Studies on products of browning reaction prepared from glucosamine, Japanese Journal of Nutrition 44(6) (1986) 307-315.

[15] R. Apak, K. Güçlü,, M. Özyürek, B. B. Oğlu, M. Bener, Cupric ion reducing antioxidant capacity assay for food antioxidants: Vitamins, polyphenolics, and flavonoids in food extracts, Methods in Molecular Biology, 477 (2008) 163-193
[16] M. Özyürek, K. Güçlü, R. Apak, The main and modified CUPRAC methods of antioxidant measurement, TrAC Trends in Analytical Chemistry, 30(4) (2011) 652-664.

[17] N. P. Seeram, M. Aviram, Y. Zhang, S. M. Henning, L. Feng, M. Dreher, and D. Heber, Comparison of antioxidant potency of commonly consumed polyphenolrich beverages in the United States, Journal of Agricultural and Food Chemistry, 56(4) (2008) 1415-1422.

[18] M. Antolovich, P. Prenzler, K. Robards, D. Ryan, Sample preparation in the determination of phenolic compounds in fruits, Analyst, 125(5) (2000) 989-1009.

[19] M. Dimitrijevic, V. S. Jovanovic, J. Cvetkovic, T. MihajilovKrstev, G. Stojanovic, V. Mitic, Screening of antioxidant antimicrobial and antiradical activities of twelve selected Serbian wild mushrooms, Analytical Methods, 7(10) (2015) 4181-4191.

[20] Y. S. Velioglu, G. Mazza, L. Gao, B. D. Oomah, Antioxidant activity and total phenolics in selected fruits, vegetables, and grain products, Journal of Agricultural and Food Chemistry, 46(10) (1988) 4113-4117.

[21] A. Michalak, Phenolic compounds and their antioxidant activity in plants growing under heavy metal stress Polish Journal of Environmental Studies, 15(4) (2006) 523-530.

[22] A. R. Leal, L. Barros, J. C. M. Barreira, M. J. Sousa, A. Martins, C. Santos-Buelga, I. C. F. R. Ferreira, Portuguese wild mushrooms at the 'pharma-nutrition' interface: Nutritional characterization and antioxidant properties, Food Research International, 50(1) (2013) 1-9.

[23] A. C. Martins, L. Bukman, A. M. M. Vargas, É. O. Barizão, J. C. G. Moraes, J. V. Visentainer, V. C. Almeida, The antioxidant activity of teas measured by the FRAP method adapted to the FIA system: Optimising the conditions using the response surface methodology, Food Chemistry, 138(1) (2013) 574-580.

[24] A. Z. Woldegiorgis, D. Abate, G. D. Haki, G. R. Ziegler, Antioxidant property of edible mushrooms collected from Ethiopia, Food Chemistry, 157 (2014) 30-36.

[25] I. C. Ferreira, P. Baptista, M. Vilas-Boas, L. Barros, Freeradical scavenging capacity and reducing power of wild edible mushrooms from northeast Portugal: Individual cap and stipe activity. Food Chemistry, 100(4) (2007) 15111516.

[26] G. Jaworska, K. Pogoń, A. Skrzypczak, E. Bernaś, Composition and antioxidant properties of wild mushrooms Boletus edulis and Xerocomusbadius prepared for consumption, Journal of Food Science and Technology, 52(12) (2015) 7944-7953.

[27] A. A. F. Zielinski, C. W. I. Haminiuk, A. Alberti, A. Nogueira, I. M. Demiate, D. Granato, A comparative study of the phenolic compounds and the in vitro antioxidant activity of different Brazilian teas using multivariate statistical techniques, Food Research International, 60 (2014) 246254.

[28] H. F. Kaiser, The Application of Electronic Computers to Factor Analysis Educational and Psychological Measurement, 20(1) (1960) 141-151.

[29] Ø. Hammer, H. A. T. David, P. D. Ryan, Past: paleontological statistics software package for education and data analysis, Palaeontologia Electronica, 4(1) (2001) $1-9$. 


\section{Izvod \\ PROVERA ANTIOKSIDATIVNE AKTIVNOSTI ŠEST VRSTA DIVLJIH PEČURAKA}

Marija V. Dimitrijević, Violeta D. Mitić, Vesna P. Stankov-Jovanović, Jelena S. Nikolić, Gordana S. Stojanović

(ORIGINALNI NAUČNI RAD)

Univerzitet u Nšu, Prirodnomatematički fakultet, Departman za hemiju, Niš,

U ovom radu prikazani su rezultati ispitivanja antioksidativne aktivnosti šest vrsta divljih pečuraka (Boletus edulis Bull., Boletus regius Krombh., Leccinum pseudoscaber Kallenb., Boletus impolitus Fr., Lactarius volemus Fr., and Lactarius deliciosus (L.) Gray) poreklom iz Srbije. Boletus regius je pečurka koja je pokazala najbolje rezultate u skoro svim primenjenim testovima, $33.0 \pm 0.1 \mathrm{mg}$ TE/g za DPPH test; $1.35 \pm 0.02 \mathrm{mg} \mathrm{AAE} / \mathrm{g}$ za TRP; $13.42 \pm 0.08 \mathrm{mg}$ Fe/g za FRAP; $37.5 \pm 0.2 \mathrm{mg}$ TE/g za CUPRAC; $243.1 \pm 5.1 \mathrm{mg}$ GAE/g za TPC). Sa druge strane, Lactarius volemus je vrsta koja pokazuje najmanju antioksudativnu aktivnosti. Na osnovu dobijenih vrednosti može se zaključiti da analizirane vrste pečuraka poseduju redukcione sposobnosti što ih čini dobrim izvorom prirodniih antioksidanasa. Rad je upotpunjen hemometrijskom analizom kako bi se bolje sagledala veza između antioksidativne aktivnosti i analiziranih vrsta pečuraka.
Ključne reči: pečurke, antioksidativna aktivnost, sadržaj fenola, hemometrijska analiza. 